\title{
Nursing care for patients at end of life in the adult intensive care unit
}

\author{
Mary Harris, J oAnne Gaudet, Caroline O'Reardon \\ Houston Methodist Hospital, Houston, Texas, USA. \\ Correspondence: Mary Harris. Address: 6565 Fannin, Medical Intensive Care Unit, Houston, Texas 77030, USA. \\ Email: MLHarris@houstonmethodist.org
}

Received: January 29, 2014

Accepted: March 28, 2014

Online Published: April 23, 2014

DOI : $10.5430 /$ jnep.v4n6p84

URL: http://dx.doi.org/10.5430/jnep.v4n6p84

\section{Abstract}

The care patients receive at the end of life in the intensive care unit (ICU) is highly dependent on the ICU nurse's knowledge, skill, and comfort level in caring for the dying patient and the patient's family. However, formal nursing education supports the acute care culture with little or no curriculum offered on end-of-life care. A search for national standards and best practices and participating in the July 2010 End-of-Life Nursing Education Consortium (ELNEC) Train the Trainer conference led to a needs assessment on how best to educate nurses on quality end of life care in the ICU setting. By identifying the nursing education and skills needed for quality end-of-life care in the ICU on the basis of best practices and national standards, ICU nurses can be empowered to provide optimal end-of-life care. Staff education and development is a key strategy for implementing evidenced-based end-of-life care in the ICU setting. Investing in ELNEC training, using available tools such as the IPAL-ICU screening tool to identify unmet palliative needs, training end-of-life resource nurses for specific hospital units, and offering education for hospital staff can begin to raise awareness regarding end-of-life care and change the existing culture. Developing an evidenced-based order set to treat symptoms of the dying patient can help to ensure that such patients' symptoms are well managed. A willingness to take information about the end of life to the community, such as a partnership with a local nursing school, is a key strategy for filling the gaps in knowledge in end of life care.

\section{Key words}

Intensive care nurse, End-of-life, critical care, Palliative care, Comfort care

\section{Introduction}

The care patients receive at the end of life in the intensive care unit (ICU) is highly dependent on the ICU nurse's knowledge, skill, and comfort level in caring for the dying patient and the patient's family. Considering that few nurses receive formal training in end-of-life care, nurses may perceive the care they provide for their patients and families as inadequate or less than optimal. Furthermore, the focus of the ICU environment is on life-preserving efforts, making it difficult for health care providers to shift their treatment goals from curative to palliative or comfort measures. The transition from curative to comfort care requires excellent clinical and communication skills from all caregivers. Because nurses are the caregivers who provide the most direct care and spend the most time with patients and their families, it is essential they feel empowered and are given the necessary education and support to provide optimal end-of-life care. 
Trying to find the best practices and resources available as well as the steps to providing excellent end-of-life care can be a daunting task for the ICU nurse. This article will identify professional standards and guidelines for end of life care, strategies for ICU nursing education, and implementation of an order set for end-of-life symptom management.

\subsection{Background and significance}

Early in 2010, through informal conversations and formal meetings with ICU nurses in a large, urban, tertiary teaching hospital, stories were elicited about the experiences nurses had with "good" and "bad" deaths in the ICU setting. These conversations were emotionally charged, with many nurses shedding tears over their experiences with deaths that happened years ago. Following these conversations, a review of standards and practice guidelines was conducted to identify best practices to provide excellent end-of-life care in the ICU setting. Simultaneously, several ICU nurses attended the End-of-Life Nursing Education Consortium (ELNEC) Train the Trainer conference (July 2010) to acquire the skills and knowledge needed to help prepare their peers to provide quality care for dying patients in the ICU.

During this time frame, a joint institutional review board-approved research project was carried out by the palliative medicine department and two ICU nurses (April 1 - December 31, 2010) to screen patients in the medical and surgical ICUs by use of the IPAL-ICU (Improving Palliative Care in the ICU) screening criteria for unmet palliative care needs ${ }^{[1]}$. The screening tool was used to identify patients with complex symptom management, need for family support, advanced disease, conflicts in goals of care, prolonged ICU stay, and active stage IV malignancy. When a patient was identified as having an unmet palliative care need, the attending physician was informed that the patient met the criteria for supportive or palliative care and a palliative medicine consult was offered ${ }^{[2]}$. Through this screening process, barriers to quality end-of-life care were identified in both ICU settings consistent with those identified in the literature review. This study further raised awareness of the need for resource nurses in the ICU to help with end-of-life education.

\subsection{Review of professional standards and guidelines}

Professional organizations such as the American Association of Critical Care Nurses (AACN) ${ }^{[3]}$ and the American Nurses Association (ANA) ${ }^{[4]}$ recognize the significance of the ICU nurse's need for knowledge and skill when providing end-of-life care and accordingly have published protocols and position statements to help guide nurses in expanding their role in end-of-life care. In 2000, a national education initiative, administered by the American Association of Colleges of Nursing (AACN) was created to improve palliative care. This initiative, called the End-of-Life Nursing Education Consortium (ELNEC), focuses on training nurses in palliative care so they can "teach this essential information to nursing students and practicing nurses" ${ }^{[5]}$. The American Association of Colleges of Nursing in their 2008 "Essentials of Baccalaureate Education for Professional Nursing Practice" identified the need for education addressing end-of-life issues such as "symptom management, support of rituals, and respect for patient and family preferences" ${ }^{[6]}$. The National Consensus Project published "Clinical Practice Guidelines for Quality Palliative Care” in 2009 to provide an "educational framework and blueprint for the structure and provision of palliative care" ${ }^{[7]}$. These guidelines may be implemented in an ICU setting regardless of whether a formal palliative care team is in place. The Center to Advance Palliative Care (CAPC) initiated the Improving Palliative Care in the ICU (IPAL-ICU) to promote excellent end-of-life care in the ICU setting and offers conferences as well as extensive on-line resources for health care providers. The Robert Woods Johnson Foundation (RWJF) in 2003 supported the RWJF Critical Care End-of-Life Peer Workgroup that identified "Seven End-of-Life Care Domains Associated with Quality Indicators and Related Clinician and Organizational Interventions/Behaviors ${ }^{[8]}$. These seven domains recommend interventions or behaviors that are aimed at improving the quality of end-of-life care in the ICU setting.

\subsection{Review of literature}

Three themes emerged when evaluating barriers to quality end of life care in the ICU setting. These were categorized as health care provider barriers, patient- and family-related barriers, and institutional barriers ${ }^{[9-11]}$. 
Health care provider barriers include lack of training for the ICU nurse and poor role models when dealing with death and dying. ICU nurses report feeling uncomfortable with death and dying and many have a death-defying attitude that only focuses on cure. Many nurses have a lack of experience with death and report that dealing with death is uncomfortable because they fear their own mortality. ICU nurses may also be uncomfortable with death owing to their own personal experiences. Poor communication skills are another barrier to providing excellent end-of-life care.

Patient- and family-related barriers include reluctance on the patient and family's part to address end-of-life issues. The patient may not be ready to die or is very young. The patient and family may have unrealistic expectations of the health care providers or lack of trust. Furthermore, disagreements over goals of care, no advance directives, or language and cultural barriers may contribute to poor end-of-life care.

Barriers from an institutional perspective include lack of leadership support for end-of-life or palliative care and a culture that does not support end-of-life care in the ICU setting. Poor continuity of care, time constraints, and lack of space or privacy to talk about end-of-life issues with the patient and family may contribute to poor-quality end-of-life care. Having no protocol for treating the dying patient's symptoms and lack of communication are additional barriers to quality end-of-life care.

Care for the dying patient in the ICU setting is described as emotional labor ${ }^{[12]}$, and dealing with death may cause ICU nurses to face their own mortality. Providing education on self-care and support to help ICU nurses address personal fears about death and dying may increase their ability to manage their emotions and strengthen coping strategies. Hinderer reported a strong correlation between coping and years of clinical practice ${ }^{[13]}$. The challenge lies in preparing the novice nurse to cope with the emotional labor of caring for the dying patient. Identification of role models skilled in end-of-life care may be a key to assisting novice nurses in managing such emotional labor.

Education is needed around the common symptoms of impending death ${ }^{[14]}$ to ensure that a comfortable death is made possible through effective symptom management. The most common symptoms during the last 3 to 5 days of life are (1) severe fatigue, (2) severe dyspnea, (3) severe pain, (4) decreased capacity for complex communication, (5) anorexia, (6) respiratory changes, (7) accumulation of respiratory tract secretions, and (8) terminal delirium ${ }^{[15]}$. The ELNEC offers focused training for nurses aimed at increasing palliative care and should meet this need.

Another opportunity for education and skill development is in the area of communication. Plonk and Arnold state that "excellent communication is essential during the dying process. Bereaved families identified improved communication, around the time of death, as the single most important means of improving end-of-life care" ${ }^{[14]}$. Arnold et al describe "Five Fundamental Principles for Better Communication" that practitioners can use to facilitate effective communication with the dying patient and the family ${ }^{[16]}$. These principles encourage two-way communication, assist the ICU nurse to understand how patients and families receive information and to understand the use of reflection to gain insight, assist in addressing emotions, and help the ICU nurse evaluate how patients and families make decisions.

\section{Methods}

An end of life nursing consortium was formed at the hospital by using the nurses who attended the ELNEC conference as trainers. Each nursing unit was encouraged to identify a liaison nurse to attend monthly meetings and receive training. Through the consortium, an end of life conference was developed to provide education to all nurses and inter-professional staff. This 8-hour conference addressed early detection, screening, and identification of patients with life-limiting illness, common indicators of end-stage disease (see Table 1), easing the burden of physical and nonphysical suffering, communication strategies, and self-care tips. Extensive written resources were provided in a binder for the health care professionals to have as a reference. The consortium nurses offered the conference twice a year to hospital employees. 
Table 1. Common Indicators of End-Stage Disease (Hospice Indicators)*

\begin{tabular}{|c|c|c|}
\hline Renal Disease & Pulmonary Disease (COPD) & Dementia \\
\hline $\begin{array}{l}\text { Creatinine clearance }<10 \mathrm{ml} / \mathrm{min} \\
(<15 \mathrm{ml} / \mathrm{min} \text { in diabetics }) \\
\text { No dialysis, no renal transplant } \\
\text { Signs of uremia } \\
\text { Intractable fluid overload } \\
\text { Oliguria }<400 \mathrm{ml} / 24 \mathrm{hrs} \\
\text { Hyperkalemia }>7.0 \mathrm{mEq} / \mathrm{L}\end{array}$ & $\begin{array}{l}\text { Dyspnea at rest or w/ minimal activity } \\
\mathrm{FEV}_{1}<305 \text { after bronchodilators } \\
\text { Cor pulmonale/right heart failure } \\
\text { Weight loss } \\
\text { Resting tachycardia }>100 / \mathrm{min} \\
\text { Oxygen dependent }\end{array}$ & $\begin{array}{l}\text { Unable to walk } \\
\text { Urinary \& fecal incontinence } \\
\text { Nearly no speech } \\
\text { Unable to dress without assistance } \\
\text { Unable to sit or hold head up } \\
\text { Frequent infections/ hospitalizations } \\
\text { Difficulty swallowing/ eating } \\
\text { Weight loss (10\% in } 6 \text { months }\end{array}$ \\
\hline Liver Disease & Heart Disease - CHF & CVA and Coma \\
\hline $\begin{array}{l}\text { Bleeding problems } \\
\text { Serum albumin }<2.5 \mathrm{~g} / \mathrm{dl} \\
\text { Ascites despite diuretics } \\
\text { Peritonitis } \\
\text { Hepatorenal syndrome } \\
\text { Encephalopathy }\end{array}$ & $\begin{array}{l}\text { NYHA Class IV } \\
\text { Discomfort (SOB or CP) w/ minimal activity } \\
\text { Arrhythmias resistant to treatment } \\
\text { CAD/Angina resistant to treatment } \\
\text { History of cardiac arrest } \\
\text { Cardiogenic embolic CVA }\end{array}$ & $\begin{array}{l}\text { Bedridden or comatose } \\
\text { Dysphagia } \\
\text { Weight loss (despite feeding tube) } \\
\text { Frequent infections/ hospitalizations }\end{array}$ \\
\hline Cancer & Amyotrophic Lateral Sclerosis & Debility (Failure to thrive) \\
\hline $\begin{array}{l}\text { Decreased performance status } \\
\text { Hypercalcemia } \\
\text { CNS metastasis } \\
\text { Superior vena cava syndrome } \\
\text { Spinal cord compression } \\
\text { Cachexia } \\
\text { Malignant effusions }\end{array}$ & $\begin{array}{l}\text { Difficulty walking \& w/ ADLs } \\
\text { Barely intelligible speech } \\
\text { Difficulty swallowing } \\
\text { Declining nutritional status } \\
\text { Frequent infections/ hospitalizations }\end{array}$ & $\begin{array}{l}\text { Multiple comorbidities } \\
\text { Frequent infections/ hospitalizations } \\
\text { Physical/functional decline } \\
\text { Significant weight loss (10\% in } 6 \\
\text { months) } \\
\text { Dependence for most ADLs }\end{array}$ \\
\hline
\end{tabular}

*Source: ${ }^{[17]}$. Abbreviations: ADLs, activities of daily living; CAD, coronary artery disease; CNS, central nervous system; COPD, chronic obstructive pulmonary disease; CP, chest pain; CVA, cerebrovascular accident; $\mathrm{FEV}_{1}$, forced expiratory volume in $1 \mathrm{~s}$; NYHA, New York Heart Association; SOB, shortness of breath.

One learning activity used at the hospital to facilitate nurses' ability to face their own mortality was the "room exercise." During this activity, the participants were asked to imagine the room, place, or location where they might spend their last days. They were asked to identify where it is, what it would look like, who would be present, and what they specifically would want to have in the room. They were then asked to identify what they did not want present in this place. Participants were also encouraged to draw a picture of what they imagined. Not surprisingly, none of the participants drew a hospital room or ICU as the place they wanted to die.

Consortium nurses worked to improve their communication with other ICU nurse colleagues, engaging them and educating them on the role of palliative care in the ICU. Through this education and contact, many ICU nurses were encouraged to advocate for patients in need of palliative and end-of-life care.

\section{Outcomes}

Through increased conversations in the medical and surgical ICU settings regarding the palliative needs of the ICU patients, a need was identified for the creation of a standard order set to be used for improving and standardizing treatment of patient symptoms at the end of life. The palliative medicine physician and team, along with input from the ICU consortium nurses, created an evidenced-based order set that was made available to all prescribers in the hospital setting. Education to expand the use of the order set was conducted by the palliative medicine physician to the hospital medical staff. The ICU consortium nurses were instrumental in orienting the staff ICU nurses to the order set, its availability, and its applicability for use in improving treatment of end-of-life symptoms. Nurses at the hospital were introduced to the 
order set through the end-of-life conferences, shared governance retreats, and the nurse residency sessions. Additionally, the ICU nurses were encouraged to request the order set when caring for a dying patient.

An unintended outcome of the hospital end-of-life consortium was the development of a partnership with a local nursing school in 2011. These Bachelor of Science in Nursing students started an end-of-life project to support grieving parents who lost a child in childbirth with the goal of better preparing students to support these parents. As a result, the leadership group among these nursing students approached the authors of this paper. An end-of-life curriculum, some of which was based on the ELNEC program, was developed to address these students' needs. This course has been taught annually in partnership with the nursing student leadership group to provide nursing students with ongoing education focused on the end of life. Feedback from these nursing students acknowledges the importance of talking about death, teaching communication skills, addressing symptom management, and offering an opportunity for students to face their own mortality in a supportive environment.

\section{Conclusion}

ICU nurses are the ones who work most closely with the patient and the patient's family; therefore, they are in a unique position to provide emotional, physical, and spiritual support and act as an advocate for the patient and family. Understanding the ICU nurses' perceptions of the care they provide at the end of life is needed so that education and support can be tailored to their needs. In meeting the needs of these nurses, the patient and the patient's family are more likely to receive the best possible end-of-life care.

\section{References}

[1] Nelson J, Campbell M, Cortez T, et al. Implementing ICU screening criteria for unmet palliative care needs: A guide for ICU and palliative care staff. A technical assistance monograph from The IPAL-ICU project. New York: Center to Advance Palliative Care; 2013. Available from: http://www.capc.org/ipal-icu/.

[2] Sihra L, Harris M, O’Reardon C. Using the Improving Palliative Care in the Intensive Care Unit (IPAL-ICU) project to promote palliative care consultation. J Pain Symptom Manage. 2011; 42(5): 672-5. PMid:22045371 http://dx.doi.org/10.1016/j.jpainsymman.2011.08.002

[3] Medina J, Puntillo K. AACN Protocols for Practice: Palliative Care and End-of-Life Issues in Critical Care. Sudbury (MA): Jones and Bartlett; 2006.

[4] American Nurses Association [Internet]. Silver Spring (MD): American Nurses Association; 2010. Available from: http://www.nursingworld.org/MainMenuCategories/EthicsStandards/Ethics-Position-Statements/etpain14426.pdf

[5] End-of-Life Nursing Education Consortium. ELNEC Fact Sheet [Internet]. Washington (DC): American Association of Colleges of Nursing; 2013 [cited 2014 Jan 23]. Available from: http://www.aacn.nche.edu/elnec/about/fact-sheet.

[6] American Association of Colleges of Nursing [Internet]. Washington (DC): American Association of Colleges of Nursing; 2008. Available from: http://www.aacn.nche.edu/education-resources/baccessentials08.pdf; 31

[7] National Consensus Project for Quality Palliative Care. Clinical practice guidelines for quality palliative care, 2nd ed. Pittsburgh (PA): National Consensus Project; 2009. Available from: www.nationalconsen susproject.org.

[8] Clarke E, Curtis J, Luce J. Quality indicators for end-of-life care in the intensive care unit. Crit Care Med. 2003 Sep; 31(9); 2255-62. PMid:14501954 http://dx.doi.org/10.1097/01.CCM.0000084849.96385.85

[9] Granek L, Krzyzanowska M, Tozer R. Oncologists' strategies and barriers to effective communication about the end of life. J Oncol Pract. 2013 July; 9(4): e129-e134. PMid:23942929 http://dx.doi.org/10.1200/JOP.2012.000800

[10] Curtis J, Patrick D, Caldwell E. Why don't patients and physicians talk about end-of- life care? Arch Intern Med. 2000 Jun; 160 : 1690-1696. PMid:10847263

[11] Friedenberg A, Levy M, Ross S, Evans L. Barriers to end-of-life care in the intensive care unit: Perceptions vary by level of training, discipline, and institution. J Palliat Med. 2012; 15(4): 404-411. PMid:22468773

http://dx.doi.org/10.1089/jpm.2011.0261

[12] Ryan L, Seymour J. Death and dying in intensive care: Emotional labour of nurse. End of Life Journal. 2013; 3(2): 1-9. 
[13] Hinderer K. Reactions to patient death. Dimens Crit Care Nurs. 2012; 31(4): 252-259. PMid:22664886 http://dx.doi.org/10.1097/DCC.0b013e318256e0f1

[14] Plonk W, Arnold R. Terminal care: the last weeks of life. J Palliat Med. 2005; 8(5): 1042-1053. PMid:16238518 http://dx.doi.org/10.1089/jpm.2005.8.1042

[15] Ferrell B, Coyle N. Oxford Textbook of Palliative Nursing, 3rd ed. 2010. New York: Oxford Press; 2010.

[16] Arnold R. Educational Modules for the Critical Care Communication Course- A Communication Skills Training for Intensive Care Fellows [Internet]. 2010 [cited 2014 Jan 23]. Available from: http://www.capc.org/ipal/ipal-icu/professional-education.

[17] The Houston Methodist Hospital. Common Indications of End Stage Disease. Houston (TX): Houston Methodist Palliative Care Department 2010. 